Kpamma Z. E., Adjei-Kumi T., Ayarkwa J., and Adinyira E. (2017). "Strategic Considerations for Applying Choosing by Advantages in Design Process.” In: LC3 2017 Volume II - Proceedings of the 25th Annual Conference of the International Group for Lean Construction (IGLC), Walsh, K., Sacks, R., Brilakis, I.

(eds.), Heraklion, Greece, pp. 507-514. DOI: https://doi.org/10.24928/2017/0239

\title{
STRATEGIC CONSIDERATIONS FOR APPLYING CHOOSING BY ADVANTAGES IN DESIGN PROCESS
}

\author{
Zoya E. Kpamma ${ }^{1}$, Theophilus Adjei-Kumi ${ }^{2}$, Joshua Ayarkwa ${ }^{3}$, and Emmanuel Adinyira ${ }^{4}$
}

\begin{abstract}
The design process is fraught with a myriad of decision points. The outcome of these decision points is significant in discovering and generating value in the construction project delivery process. Application of a collaborative decision system, such as choosing by advantages (CBA), on these decision points, has been established to enhance value generation by enhancing participation, transparency and respect among stakeholders. However, little attention has been given to identifying strategic considerations for operationalizing CBA application across the design process spectrum.

This paper combines knowledge from the case application of CBA, on selected design decisions, with theories on design process management and lean design in identifying these strategic considerations. Significant findings, among others, is the need to stratify the design process into identifiable decision frames to form the basis for applying CBA across the design process spectrum; the use of boundary objects to enhance communication among stakeholders in CBA application in design process; and the need for clearly established project requirements at the project definition phase to provide a sound basis for the CBA process. Findings of this study should provide a practical guide for CBA application in design process towards lean design implementation.
\end{abstract}

Keywords: Choosing by advantages, design process management, value, lean design, decision frames.

\section{INTRODUCTION}

Design process is noted to significantly impact the value delivery chain in construction project delivery process. Value delivered at the construction stage of construction projects is determined at the design stage (Bertelsen et al. 2002). Discovering and generating value at the design stage of construction projects requires a strong collaboration among project participants during design. Since the design process is associated with countless and expandable decision points, stimulating collaboration among participants, for value generation, requires the adoption of a collaborative decision system in design process. The Choosing By Advantages (CBA) decision system is identified as collaborative, since it stimulates an atmosphere of transparency, respect and participation among stakeholders in design process (Arroyo et al. 2014; Kpamma et al. 2016). Though several research works have established the collaborative attributes of

\footnotetext{
Senior Lecturer, Department of Building Technology, Sunyani Technical University, Sunyani, Ghana, evanskpamma@yahoo,co.uk

2 Senior Lecturer, Department of Building Technology, Kwame Nkrumah University of Science and Technology, Kumasi, Ghana, tadjei-kumi@yahoo.com

3 Professor, Department of Building Technology, Kwame Nkrumah University of Science and Technology, Kumasi, Ghana , ayarkwajosh@yahoo.com

4 Senior Lecturer, Department of Building Technology, Kwame Nkrumah University of Science and Technology, Kumasi, Ghana, rasadii@yahoo.com
} 
CBA, little attention has been paid to identifying practical considerations to operationalize CBA application across the entire spectrum of design process.

This research, thus, set out to identify practical considerations in CBA application across the design process. Consequently, three cases of CBA application on selected design decisions were studied to obtain empirical knowledge on the functioning of CBA in design process. Empirical knowledge from the cases was further enhanced by theories on design process management and lean design in identifying strategies to apply CBA in design process. The outcome of this research should contribute to providing a practical guide in the application of CBA in design process.

\section{THEORY}

\subsection{Choosing By Advantages}

CBA is a multi-criteria decision analysis (MCDA) that, unlike other MCDAs, distinctively relies on comparing the explicit advantages of alternatives in the decisionmaking process (Suhr 1999). Advantages of alternatives are compared by assigning importance, using numerical weights, to the advantages. The alternative with the highest total Importance of Advantages (IoA) becomes the preferred choice. Though seminal application of CBA is attributed to the U.S. Forest Service (Suhr 1999), its prevalence in the construction industry, especially in lean construction research and practice, is growing steadily (e.g. Arroyo et al. 2014; Parrish and Tommelein 2009). CBA creates a participatory, transparent and collaborative atmosphere for auditable decisions in design and construction (Arroyo et al. 2013).

In most studies on CBA application in the AEC sector (e.g. Kpamma et al. 2016; Arroyo et al. 2013, 2014; Parish and Tommelein 2009), little attention is paid to identifying strategic considerations in applying CBA in design process. Furthermore, $\mathrm{CBA}$ is identified as one of the lean construction tools that are still lagging behind in terms of practice and research (Arroyo et al. 2014; SmartMarket Report 2013).

\subsection{Design Process Management}

One strategy for managing design process, in line with the concept of reflective practice in design process (Dong et al. 2013), is to identify decision-making frames within the design process to define the context for design activity (Zerjav et al. 2013). Frames, in this context, refer to the context of managerial decision-making which makes it possible for observable design action in the domain of design activity (Zerjav et al. 2013).

Accordingly, the design process is partitioned into recurring episodes of design activity occurring in corresponding decision-making frames (Figure 2). This approach aligns with the Group Decision Support (GDS) methodology of staging "a series of decision sessions scheduled to correspond with the decision points punctuating the building design process" (Green 1996). Consequently, a concern of design process management is to identify and enforce frames for present design activities, and anticipate subsequent frames for ensuing design activities (Zerjav et al. 2013). Anticipating decision frames for subsequent design activities provides an opportunity to direct design activities in a more informed way (Zerjav et al. 2013).
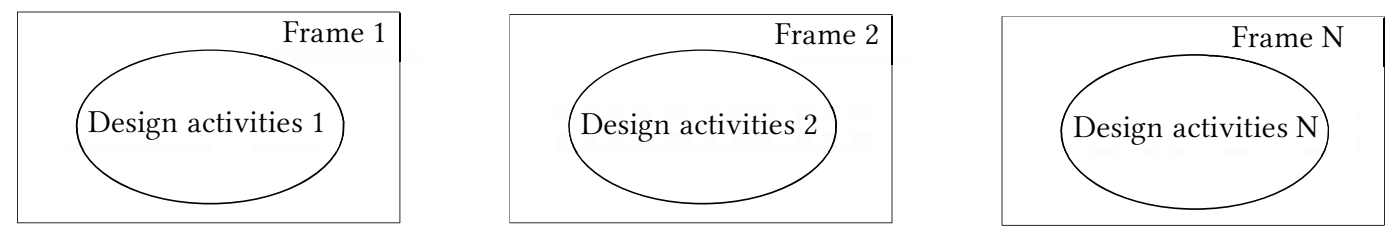


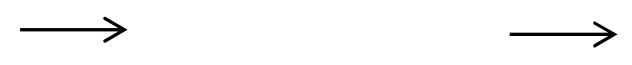

Figure 2: Decision-making frames in design processs (Zerjav et al. 2013)

The design manager is expected to rely on client/user requirements to enact the decision-making frames. Even though there are difficulties in explicitly representing the frames into observable action (Stumpf \& McDonnell 2002), it is also contended that managerial decision-making is based on observable action (Zerjav et al. 2013).

Beyond identifying and anticipating the decision frames in design process management is the concern of the outcome of the decision frames (Lawson et al, 2003). Consequently, as Suhr (1999) asserts, if the outcome of these design decisions matters, then the decision-making approach also matters. It is, thus, pertinent to employ a decision-making system, such as CBA, across the various frames. CBA, while ensuring that the output from each decision-making frame is sound, should also enhance collaboration and consensus building among stakeholders.

\section{Methodology}

The study sought to identify various strategic considerations in the application of CBA in design process. Three case studies, involving CBA application in selected design decisions were, therefore, conducted for in-depth knowledge on the functioning of CBA in design process. A case study is a research approach that intends to create detailed and concentrated knowledge about a situation or question by considering the real physical and social context of the case (Christiaans et al. 2004; Meredith, 1998; Yin 1994).

Following the action-based nature of the research in which there was the need for direct involvement of the researcher in the field (Keizer et al. 2002), a key member of the research team became an active participant in CBA application workshops for the case studies. This member participated in the workshops mainly as a facilitator, planning and moderating the processes in the workshops. The action researcher also participated in generating design options in the respective CBA applications. The use of action research afforded an opportunity for elements of CBA application process (e.g. group interaction, value concerns) to be closely studied and experienced.

The choice of three cases was based on the literal replication logic (Yin 1994). Case 1 involved the application of CBA for stakeholders to collaboratively decide on a direction of expansion of a theatre building at the Holy Family Hospital in Techiman, Ghana. Case 2 involved the application of CBA for stakeholders to collaboratively decide on a window opening system for a lecture hall complex project at Takoradi Polytechnic in Takoradi, Ghana. In case 3, CBA was applied for stakeholders to collaboratively decide on a ceiling finish for a lecture hall project at Sunyani Polytechnic in Sunyani, Ghana.

Data from the case studies was obtained through participant observation, direct observation and interviews. The use of multiple instruments for data ensured data credibility through cross-verification. The technique of pattern matching was employed in data analysis. 


\section{FINDINGS AND DISCUSSION}

Each of the cases fundamentally involved four key sessions to discuss and establish project requirements; agree on design options; introduce stakeholders to CBA steps; and apply CBA to decide on options. Participants in case 1 were mainly two members of the design team and nine representatives of the clinical and administrative users of the theatre. Participants in case 2 were mainly two members of the design team, a window installation specialist, and representatives of the client and potential users made up of two students, two lecturers, an estate officer, the director works and the polytechnic's architect. In case 3 the participants were one representative of the design team, the polytechnic's maintenance officer, three students and four lecturers as potential users of the building.

Participants in each of the cases actively participated in the CBA process, from generating options through to the final choice. Of the two design options generated in case 1, one originated from the user-group based on prior meetings among themselves, while the other option came from the design team. The options in cases 2 and 3 were agreed upon by participants largely based on availability in the Ghanaian market. Though the process of establishing the attributes of alternatives, on which the advantages were based, also involved some consultation among participants, the action researcher, as a facilitator, played a lead role in researching to obtain, especially, technical attributes of some alternatives. In all the cases, the process of obtaining correct information for explicit description of alternatives' attributes was one of the activities that dragged process. Where attributes of alternatives were not explicit enough, it led to ambiguous advantages which, in some instances, resulted in delayed consensus on IoA.

The entire CBA process, in the three cases, generally induced an atmosphere of dialogue and consensus. This enabled stakeholders to learn and understand their respective values, needs and interests. In case 1, where the option with the highest total IoA costed more, participants still adopted it, and without regret, went ahead to implement it. This was due to clarity on this option's advantages being more aligned to the project objectives. Louvered window, in case 2 , had the highest total IoA and costed least, therefore making it the obvious choice, which choice turned out to be most aligned to the objectives of the project.

Observations and interview of participants in the case studies further revealed various considerations to enhance the application of CBA in the design process. These considerations are identified and discussed below.

\subsection{Pre-design activities}

Preliminary design activities, such as requirements definition were identified to strongly impact the CBA process. Generating design options, in the case studies, was, for instance, guided by user/client requirements established at the project definition phase. The "illdefined" feature of design problems and the expandable nature of design solutions particularly make the definition of project requirements useful in controlling the generation of design options.

In case 1, for instance, client/user requirements, such as maintaining a sterile work environment, and ensuring non-interference with on-going clinical activities in the existing theatre during project execution, were established at the project definition stage, and served as critical considerations for stakeholders to determine importance of advantages during the CBA process. Pre-design activities, therefore, forms a necessary foundation in the CBA application process. 


\subsection{Boundary Objects}

Effective communication was found to be crucial in making use of the collaborative potential of the CBA process, especially when involving stakeholders in design decisions. This calls for a means for various stakeholders to effectively communicate their needs and intentions to the mutual understanding of all participants.

The use of boundary objects, in the form of animations, models or simulations, could facilitate a shared understanding when designers interact with other stakeholders at the pre-design stage or during the application of CBA at various stages of design. Animated designs could, for example, enhance a shared understanding of alternatives' attributes in the cases. An alternative's attribute is essentially the value of that alternative relative to a certain requirement; hence, a wrong appreciation of it (attribute) is detrimental to the entire value discovering process in CBA application.

\subsection{Shared Mental Models}

Consistent with theories on mental models and team performance (Badke-Schaub et al. 2007), mutual acquaintance among stakeholders, especially relative to their respective values, capabilities and roles, was essential in enabling the team processes in the cases. The freer and friendlier interaction among stakeholders in case 1 and 3, compared to that in case 2, were attributable to a higher level of acquaintance among stakeholders in case 1and 3. Most of the stakeholders in case 1 and 3 had a longer working relationship and were therefore more acquainted with one another compared to those in case 2.

An open atmosphere of interaction is unrestrictive, and encourages creativity among team members. Unrestricted creativity is particularly essential at the innovation phase of the CBA process where alternative design solutions are generated to meet stakeholder requirements. Knowledge of member expertise and capabilities also enhances team confidence in the process. In the absence of previous working relationships, holding partnering/alignment meetings can help stakeholders define, as a group, the project's conditions of Satisfaction (i.e. goals). This helps create a shared mental model for the project at hand.

\subsection{Combined Application of CBA with other Tools}

The collaborative and value generating attributes of CBA could be complemented with the use of related lean design tools, such as A3 reports, Target Value Design (TVD) and Set-Based Design (SBD). A3 reports are employed to display relevant information on an A3 size sheet for effective team communication and collaborative decision-making based on the PDCA cycle (Sobek II and Smalley 2008). In the case studies, the use of A3 reports would be supportive to stakeholders as they explored alternatives and developed ideas for discourse in the CBA process.

The central idea behind TVD is to ensure that the design process is driven by a quest to achieve a target value in the form of a desired performance for a building project, within specified cost limits agreed with the owner (Zimina et al. 2012). TVD process, which is collaborative and starts at the early stages of design, could provide a significant guide in generating design options and deciding importance of advantages in CBA. SBD fundamentally encourages the act of considering a broad set of possible design solutions and progressively narrowing the set to a desirable solution. The design team, in SBD, is expected to postpone commitment to decisions on alternatives, to allow time to explore and evaluate as many feasible design solutions as possible (Singer et al. 2009). This identifies with the CBA process in the case studies whereby design options were 
generated based on established user requirements, and commitment to them differed until they were subjected to rigorous evaluation.

\subsection{Decision-Making Frames}

CBA application requires a definition of a specific design problem. In the case studies, the CBA decision system was applied to precisely defined decision problems in the respective projects: "deciding on a direction of extension of an existing building", "deciding on a window opening system" and "deciding on a ceiling finish". This aspect of CBA application is consistent with the design process management model of identifying decision-making frames corresponding to various episodes of design activity across the design process (Zerjav et al. 2013). The GDS methodology of staging a sequence of decision sessions scheduled to correspond with the decision points which intersperse the building design process (Green 1996) also aligns with this aspect of the CBA process.

The identified decision-making frame in case 1 would be "create additional operating theatre spaces", containing the design activity, "extend existing building in a suitable direction". In case 2, the identified decision-making frame would be "provide window openings", containing the design activity, "specify/design a window opening system". In case 3 the identified decision-making frame would be "finish the ceiling system", containing the design activity, specify/design a ceiling finish. Even though the identified frames in the case studies were from different projects, they could, hypothetically, represent a series of identified decision-making frames (F1, F2 and F3) containing various design activities (D1, D2 and D3) across the design process of one project (Figure $3)$.

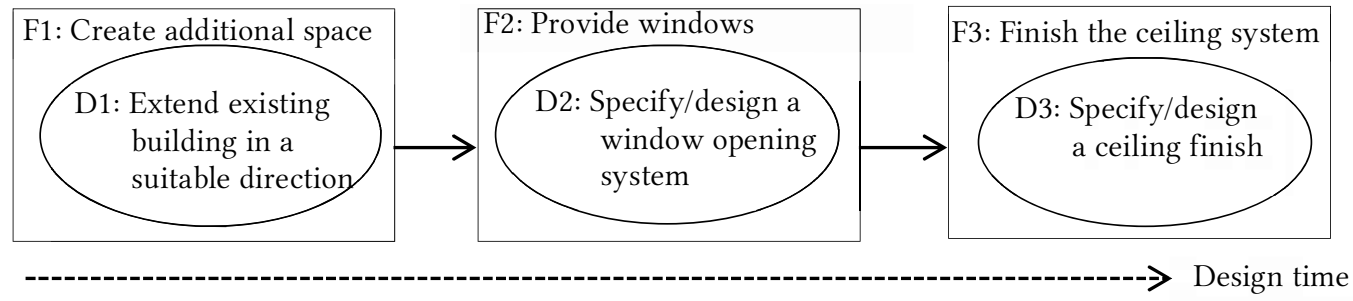

Figure 3 : Hypothetical link of Decision-making frames across case studies

The application of CBA with other lean design tools (i.e. TVD, SBD and A3) could then be decentralised across the identified decision frames. In this respect, the overall TVD for a project would, for instance, be decomposed into sub-TVDs per each decision frame. The corresponding design activity in each frame, thus, involves generating design options, in line with SBD, to form a satisfactory solution set, and the CBA process followed to rigorously evaluate and choose the desired option from the solution set. An A3 report would then be generated to provide a background to the outcome of each decision within each frame.

\subsection{CBA Application Constraints}

Notwithstanding the collaborative and value generating potential in CBA, it may be impracticable to go through the structured process of CBA to involve users for every design decision, and for all projects. Based on experience from the case studies, time and resource insufficiency could pose a limitation. Admittedly, it is more practicable to limit the CBA process to some category of projects and design decisions. 
Projects which could possibly be considered for this process include: large and complex projects with a diversity of stakeholders who could influence and be influenced by the project; projects which lack clarity on project objectives, resulting in limited knowledge and the need for user input; projects, such as hospitals, which would eventually house specialized operations, and offer highly specialized services. In determining the kind of design decision (frames) to apply the CBA process, considerations such as, high user stake in design decision; lack of adequate knowledge for decision; and high technical complexity of design decision could also be a guide.

\subsection{Facilitator}

Lessons from the case studies also illustrate the crucial role of a facilitator in the CBA application process, especially when stakeholders of diverse professional and social orientations are involved. The action researcher's role as a facilitator was instrumental in the following areas of the process: training participants in the CBA process; identifying and bringing relevant stakeholders together; planning and coordinating workshops and meetings; researching for decision data, especially on the attributes of alternatives.

Proficiency in CBA application, an understanding of design process, and good interpersonal skills are essential in the facilitator role. The facilitator, for instance, based on his experience in design process and stakeholder participation, should lead the process of identifying, anticipating and enforcing decision-making frames during the CBA process.

\section{CONCLUSIONS}

CBA remains an emergent decision system in lean construction research and practice. Though the collaborative attributes of CBA is established in lean construction body of knowledge, strategies for operationalizing its application in design process have received less attention. Based on empirical knowledge from the case application of CBA in the design of three projects, combined with some theories in design management, a number of strategic considerations have been identified in this paper to serve as a guide in operationalizing CBA application in design process.

Among others, the findings in this paper provides a practical guide on organizing the application of CBA across the design process spectrum by relying on the concept of decision framing in design process management. The outcome of this research can help contribute to the theory and practice of lean design management. Though the findings of this study draws on empirical data from three case studies, some of the identified strategies, for CBA application in design process, are limited by the absence of an empirical evaluation of their workability.

\section{REFERENCES}

Arroyo, P., Tommelein, I. D., \& Ballard G. (2014). Comparing AHP and CBA as decision methods to resolve the choosing problem in detailed design. J. Constr. Eng. Manage. 141(1).

Arroyo, P., Tommelein, I., and Ballard, G. (2013). Using Choosing By Advantages to Select Ceiling Tile From a Global Sustainable Perspective. Proc. IGLC 21, Fortaleza, Brazil. 
Badke-Schaub, P., Neumann, A., Lauche, K., \& Mohammed, S. (2007). Mental models in design teams: A valid approach to performance in design collaboration? CoDesign, 3(1), 5-20.

Bertelsen, S., Fuhr Petersen, K. and Davidsen, H. (2002). Bygherren som forandringsagent - på vej mod en ny byggekultur (The Client as Agent for Change Towards a New Culture in Building). Byggecentrum, Copenhagen, Denmark

Christiaans, H.H.C.M., Fraaij, A.L.A., Graaf, E. de \& Hendriks, C.F. (2004). Methodology of Scientific Research. Lemma, Utrecht

Dong, A., Kleinsmann, M. S., \& Deken, F. (2013). Investigating design cognition in the construction and enactment of team mental models. Design Studies, 34(1), 1-33.

Green, S. (1996). A metaphorical analysis of client organizations and the briefing process. Constr. Manage. \& Econ., 14(2), 155 - 164.

Keizer, J., Halman, J. I. M., and Song, X. (2002). "From experience: Applying the risk diagnosing methodology." J. Prod. Innov. Manage., 19(3), 213-232.

Kpamma, Z., Adinyira, E., Ayarkwa, J., and Adjei-Kumi, T. (2016). Application of the CBA Decision System to Manage User Preferences in the Design Process. J. Prof. Issues Eng. Educ. Pract. , 142 (1). doi.org/10.1061/(ASCE)EI.1943-5541.0000258.

Lawson, B., Bassanino, M., Phiri, M. and Worthington, J. (2003). Intentions, practices and aspirations: Understanding learning in design. Design Studies, 24(4), 327-339.

Meredith, J. (1998). Building operations management theory through case and field research. Journal on Operations Management, 16, 441-454.

Parrish, K., Tommelein, I. D. (2009). "Making design decisions using Choosing By Proc. IGLC 17, Taipei, Taiwan.

Singer, D.J., N. Doerry, and M.E. Buckley (2009). "What Is SetBased Design?” Naval Engineers Journal, 121 (4) 31-43.

SmartMarket Report. (2013). Lean construction: Leveraging collaboration and advanced practices to increase project efficiency. Bedford, MA: McGraw Hill Construction.

Sobek II, D. K., and Smalley, A. (2008). Understanding A3 Thinking: A Critical Component of Toyota's PDCA Management System, Taylor \& Francis Group, LLC, New York, NY, 186 pp.

Suhr, J. (1999). The Choosing By Advantages Decision making System. Quorum, Wesport, CT.

Yin, R.K. (1994). Case Study Research: Design and Methods. Sage, London

Zerjav, V., Hartmann, T., \& Achammer, C. (2013). Managing the process of interdisciplinary design: identifying, enforcing and anticipating decision-making frames. Archit. Eng. \& Des. Manage., 9(2), 121-133.

Zimina, D., Ballard, G., \& Pasquire, C. (2012). Target value design: Using collaboration and a lean approach to reduce construction cost. Constr. Manage \& Econ, 30, $393-$ 398. 